Лебедева Н. А.

Аннотация. Цель исследования - проанализировать действующую нормативно-правовую базу на предмет соответствия современным требованиям к языковой подготовке пилотов гражданской авиации и авиадиспетчеров. В статье представлены комментарий компетентностной модели выпускника вуза гражданской авиации по специальности «Аэронавигация» и изучение актуальных российских и международных правовых актов, регулирующих профессиональную деятельность авиаспециалистов. Научная новизна заключается в выявлении недостаточной согласованности перечня компетенций федеральных государственных образовательных стандартов (ФГОС) с заявленными результатами освоения общей образовательной программы по авиационному английскому языку и несоответствия содержания самих компетенций Шкале оценки языковых знаний Международной организации гражданской авиации (ИКАО). В результате даны конкретные рекомендации по решению этих противоречий с акцентом, прежде всего, на отсутствии нормативной базы при формировании перечня профессиональных компетенций.

EN Competence-Based Model

\title{
of Future Pilots' and Air Traffic Controllers' Foreign-Language Education in the Light of the Requirements of Newly Adopted Normative Legal Acts
}

\section{Lebedeva N. A.}

Abstract. The paper examines the current normative-legal base with a view to identify how it satisfies modern requirements for the foreign language competence of civil pilots and air traffic controllers. The article describes a competence-based model of a university graduate of the "Aeronavigation" speciality and analyses the current Russian and international legal acts regulating airmen's professional activity. Scientific originality of the study lies in the fact that the author reveals discrepancies between requirements of the Federal State Educational Standards and targeted outcomes of the "Aviation English" basic educational program, identifies discrepancies with the ICAO (International Civil Aviation Organization) Language Proficiency Rating Scale. The research findings are as follows: the author provides recommendations on how to eliminate these contradictions emphasizing absence of a normative base to form a list of professional competences.

\section{Введение}

Эффективное иноязычное обучение всегда было важнейшим компонентом образовательного процесса в вузах гражданской авиации (ГА), и прежде всего это относится к подготовке будущих пилотов и авиадиспетчеров, поскольку хорошее знание английского языка для данной категории специалистов является тем необходимым условием, которое позволяет оставаться им в состоянии коммуникативной пригодности при выполнении профессиональных обязанностей. Подобное утверждение - не лозунг: по данным экспертов, за последние 50 лет в авиакатастрофах, произошедших исключительно из-за недопонимания, возникшего между пилотом и авиадиспетчером по причине плохого знания английского языка, погибло около 2000 человек [4]. Учитывая это обстоятельство, Международная организация гражданской авиации ИКАО (от англ. ICAO - International Civil Aviation Organization) ввела в 2011 году единые требования к владению языком (Language Proficiency Requirements, LPR) и обязательный экзамен для пилотов и авиадиспетчеров на получение сертификата ICAO Language Proficiency Level 4 по английскому языку [15]. В соответствующем «Руководстве по внедрению требований ИКАО к владению языком» [Там же] представлена измерительная квалификационная шкала 
языковых знаний, состоящая из несколько уровней, которая используется для оценки демонстрируемых навыков. Для пилотов и авиадиспетчеров «рабочим» уровнем является 4-й, и именно ему должны соответствовать языковые умения выпускника вуза ГА. Официально об этом было заявлено в мае 2011 года в СанктПетербургском государственном университете ГА на международном семинаре ИКАО по вопросам внедрения требований к владению английским языком с участием руководства ИКАО и представителей более чем 20 стран.

Авиаспециалисты не раз отмечали, что существует прямая зависимость безопасности полетов от уровня знаний авиационного английского (Aviation English Language), соответствующей фразеологии и правил ведения радиотелефонной связи на английском языке непосредственными участниками полета [1; 3; 6-8; 17-20; 21, p. 6]. Именно поэтому ИКАО и Росавиация ведут непрерывный мониторинг языковой подготовки выпускников образовательных учреждений гражданской авиации. Результаты своих наблюдений они представляют в ежегодных отчетах по безопасности ИКАО [22] и на регулярно проводимых форумах.

Так, в марте 2020 года в Москве состоялась специализированная конференция по совершенствованию обучения английскому языку в учебных заведениях гражданской авиации и тестирования по шкале ИКАО. Организатором конференции выступило Федеральное агентство воздушного транспорта (Росавиация). Предварительно руководителям соответствующих подразделений вузов, ведущих подготовку специалистов по направлению «Аэронавигация», Агентством было разослано Распоряжение от 18.02.2020, в котором предлагалось, во-первых, высказать свои предложения по интеграции языковой подготовки в учебный процесс, а во-вторых, создать рабочие группы «для разработки перечня профессиональных компетенций в области профессионально-ориентированного языкового образования и программ следующего поколения в образовательном учреждении» [14].

Необходимость безотлагательного принятия мер по реформированию системы обучения пилотов и диспетчеров английскому языку в высших и средних профессиональных учебных заведениях гражданской авиации была обозначена рядом крупнейших специалистов, в том числе генеральным директором Международного консультативно-аналитического агентства «Безопасность полетов» С. А. Мельниченко, экспертом Н. П. Мельниченко, членом Координационного совета ветеранских организаций при Росавиации Ю. П. Дарымовым и др.

Суть проблемы заключается в том, что языковая подготовка будущих пилотов и авиадиспетчеров в настоящее время оценивается отечественными представителями авиаотрасли как недостаточно удовлетворительная, причем претензии эксперты предъявляют как к наполнению учебно-методических комплексов, так и к самой методике преподавания английского языка. По мнению Н. П. Мельниченко [5], используемые сейчас в учебном процессе пособия и учебники мало отвечают современным целям обучения, некоторые из них безнадежно устарели, а некоторые откровенно лишены специфической направленности. Методика же обучения авиационному английскому языку, фразеологии радиообмена, применяемая в вузах ГА, к сожалению, практически не учитывает последние достижения отечественной и зарубежной теории и практики преподавания Aviation English. Кроме того, на конференции затрагивался вопрос и о несоответствии требований отечественных образовательных стандартов требованиям ИКАО, изложенным в «Руководстве по внедрению требований ИКАО к владению языком», а также национальным нормативно-правовым документам.

В настоящей статье мы коснемся последнего вопроса, поскольку, по нашему мнению, реформирование системы языковой подготовки в вузах ГА следует начинать именно с уточнения нормативно-правовых аспектов. Актуальность подобного исследования связана в первую очередь с необходимостью документального обоснования несоответствия действующих образовательных стандартов, регламентирующих обучение английскому языку в вузах ГА, высоким требованиям, которые заявлены Международной организацией гражданской авиации (ИКАО) и авиационной отраслью в целом. Автор настоящей статьи присутствовал на указанной конференции и выступал с докладом перед аудиторией высококлассных специалистов, которые подтвердили значимость данной проблемы.

Задачи:

- провести анализ нормативно-правовых актов, регулирующих осуществление образовательной деятельности в вузах ГА на современном этапе, действующей учебно-программной документации;

- $\quad$ рассмотреть трудности, возникающие в ходе проектирования основных образовательных программ (ООП) в контексте введения новой версии федеральных государственных образовательных стандартов (ФГОС);

- произвести подробный содержательный разбор перечня профессиональных компетенций, предлагаемых действующим ФГОС и имеющих непосредственное отношение к языковой подготовке будущих пилотов и авиадиспетчеров.

Методы исследования: теоретический анализ научно-методической и специальной литературы по проблеме исследования, анализ профессиональных стандартов и федеральных государственных образовательных стандартов, действующей учебно-программной документации, организационных и методических материалов, приемы дефиниционного анализа. В теоретическую базу исследования легли концептуальные идеи профессиональной деятельности Б. Г. Ананьева, А. Г. Ковалева, В. Н. Мясищева и др.

Теоретическая и практическая основа исследования. В качестве материала исследования мы привлекаем основные образовательные программы двух ведущих авиационных вузов: Санкт-Петербургского государственного университета гражданской авиации (СПбГУ ГА) и Ульяновского государственного института гражданской авиации им. Б. П. Бугаева (УИ ГА). Сами ООП, как и сведения о компетентностных моделях выпускников, извлечены из открытых источников - сайтов данных вузов [12; 13].

Практическая значимость: результаты проведенного анализа позволят сформулировать рекомендации по актуализации ФГОС, разработке новой компетентностной модели выпускника вуза ГА по специальности 
«Аэронавигация», максимально учитывающей дескрипторы языковых умений квалификационной шкалы языковых знаний ИКАО.

\section{Обзор регламентирующих документов}

Федеральный закон «Об образовании в Российской Федерации» предъявляет определенные требования к формированию набора компетенций, на развитие которых направлена образовательная программа по любой специальности. Все эти требования, согласно Федеральному закону от 02.05 .2015 № 122 «О внесении изменений в Трудовой кодекс РФ и статьи 11 и 73 Федерального закона “Об образовании в Российской Федерации”», должны основываться на профессиональных стандартах и согласовываться с общими трудовыми функциями [10].

Профессиональный стандарт (ПС) - это новая форма определения квалификации работника, приходящая на смену Единому тарифно-квалификационному справочнику работ и профессий рабочих и Единому квалификационному справочнику должностей руководителей, специалистов и служащих.

Одной из основных целей разработки ПС является создание объективной основы для формирования программ высшего образования - начиная от ФГОС и заканчивая рабочими программами дисциплин в конкретном вузе. Так, в ПС указывают наименование, основную цель вида профессиональной деятельности, а ФГОС содержит краткое описание профессиональной деятельности выпускников. Именно в этом пункте должно быть максимальное пересечение требований важнейших документов, регламентирующих высшее образование.

Следующий пункт, который наиболее важен при параллельном рассмотрении обоих документов, ПС и ФГОС, - это максимально скорректированное соотнесение заявленных, с одной стороны, в ПС обобщенных трудовых функций соответствующего уровня, требований к знаниям и умениям и, с другой стороны, планируемых результатов освоения образовательной программы в ФГОС.

Наконец, третий пункт, на который следует обратить основное внимание при соотнесении ПС и ФГОС, это трудовые функции, трудовые действия, прописываемые в ПС, и направленность (профиль), а также типы профессиональных задач и объектов профессиональной деятельности, декларируемые в ФГОС.

Эти три пункта очень важны для составления конкретной ООП по специальности, так как ПС рассматривается сейчас как обязательное условие разработки программ (дисциплин, модулей), обеспечивающих готовность выпускника вуза к выполнению того или иного вида профессиональной деятельности (трудовых функций).

И в этой связи следует отметить, что наибольшая проблема, с которой сталкиваются вузы, отвечающие за подготовку пилотов ГА, - это отсутствие большинства отраслевых ПС. Профессиональные компетенции выпускника вуза ГА должны формироваться в ООП, согласно законодательным документам, преимущественно на основе содержания ПС, конкретно - на основе перечня общих трудовых функций, но такового в настоящее время для пилотов и авиадиспетчеров не существует. К этому необходимо добавить, что согласование новых образовательных тенденций в подготовке указанных специалистов корректируется, а иногда тем самым и осложняется обязательным перечнем международных требований ИКАО. Каков же выход из данной ситуации для составителей конкретных ООП авиационных вузов?

В том случае, когда ПС отсутствуют или не в полной мере отражают область профессиональной деятельности, к которой вуз готовит выпускника, согласно регламентирующим документам, отмечает Р. Р. Биглов, образовательная организация имеет полное право сформировать перечень профессиональных компетенций «на основе форсайт-анализа компетенций, предъявляемых к выпускникам данного направления подготовки на рынке труда, обобщения зарубежного опыта, проведения консультаций о перспективах развития системы квалификаций с ведущими работодателями, объединениями работодателей отрасли» [2]. Для вуза, ведущего подготовку пилотов и авиадиспетчеров ГА, в этом случае, конечно же, ведущими документами являются документы Международной организации ИКАО, на которые и ориентировались составители действующего ФГОС.

\section{Требования действующего ФГОС}

Рассмотрим требования ФГОС к результатам обучения профессионально ориентированному английскому языку пилотов квалификации (степени) «бакалавр», специальность «Аэронавигация», профиль «Гражданская авиация», подготовку которых осуществляют СПбГУ ГА и УИ ГА. Естественно, что мы, таким образом, переходим на рассмотрение конкретных компетенций, сформированность которых и означает результат педагогической деятельности вуза. Сразу следует отметить, что на данный момент актуальными являются только ФГОС 3, т.е. ФГОС ВПО, ФГОС ВО 3+ и 3++, которые для других специальностей уже активно принимаются к исполнению, в авиационном образовании существуют только в проектах.

Всего в ФГОС ВПО по направлению подготовки 161000 АЭРОНАВИГАЦИЯ (квалификация (степень) «бакалавр») [16] указано 144 компетенции, которые должны быть сформированы по результатам обучения у будущих пилотов. Из этих компетенций только 6 имеют непосредственное отношение к языку вообще, а к английскому - 3. Из трёх компетенций 2 являются общекультурными (ОК), и только одна - профессиональной (ПК) (см. Табл. 1).

Под вопросом остается отнесенность к области иноязычного образования ОК-55, согласно которой выпускник авиационного вуза должен обладать «способностью и готовностью к подготовке и редактированию текстов профессионального и социально значимого содержания» [Там же], хотя умение пилота читать и правильно интерпретировать техническую документацию новейшего авиационного оборудования является 
важнейшим требованием современной авиационной отрасли. Относительно же указанных компетенций отметим сразу, что они полностью соответствуют требованиям Шкалы оценки языковых знаний ИКАО четвертого (рабочего) уровня [15, с. A-7, 8].

Таблица 1. Компетенции, имеющие непосредственное отношение к английскому языку, в ФГОС ВПО по направлению подготовки 161000 АЭРОНАВИГАЦИЯ (квалификация (степень) «бакалавр»)

\begin{tabular}{|c|l|}
\hline $\begin{array}{c}\text { Код формируемой } \\
\text { компетенции }\end{array}$ & \multicolumn{1}{c|}{ Содержание } \\
\hline ОК-51 & $\begin{array}{l}\text { знать английский язык в объеме не менее 4000 учебных лексических единиц общего и терми- } \\
\text { нологического характера }\end{array}$ \\
\hline ОК-52 & владеть английским языком в объеме, достаточном для эффективного общения на общие темы \\
\hline ПК-10 & $\begin{array}{l}\text { владеть авиационным английским языком в объеме, достаточном для эффективного общения } \\
\text { на общие, конкретные и связанные с работой темы }\end{array}$ \\
\hline
\end{tabular}

Согласно действующему ФГОС, предусматриваются только 2 дисциплины, которые охватывают англоязычную подготовку будущих пилотов и авиадиспетчеров: «Английский язык» и «Авиационный английский». «Английский язык» включен в Базовую часть (шифр Б.1) «Гуманитарного, социального и экономического цикла», а «Авиационный английский» входит в «Профессиональный цикл» в базовой (общепрофессиональной) его части (индекс Б.3).

Вуз вправе вводить и другие лингвистические дисциплины, однако только на правах компонентов вариативной части ООП. Два ведущих авиационных вуза страны отдали такие права следующим дисциплинам: «Фразеология радиообмена на английском языке при выполнении полетов», «Фразеология радиообмена на английском языке», «Правила и фразеология радиообмена при выполнении полётов», «Фразеология радиообмена и радиотелеграфия», «Разговорный английский язык».

Теперь обратимся к рассмотрению компетенций, на формирование которых направлено все иноязычное обучение по направлению подготовки 161000 АЭРОНАВИГАЦИЯ (квалификация (степень) «бакалавр») (см. Табл. 2).

Таблица 2. Компетентностная модель иноязычного образования будущих пилотов и авиадиспетчеров ФГОС ВПО по направлению подготовки 161000 АЭРОНАВИГАЦИЯ (квалификация (степень) «бакалавр»)

\begin{tabular}{|c|c|c|c|}
\hline \multicolumn{2}{|c|}{ СПБГУ ГА } & \multicolumn{2}{|c|}{ УИ ГА } \\
\hline \multicolumn{2}{|c|}{ Иностранный язык (Английский язык) } & \multicolumn{2}{|c|}{ Английский язык } \\
\hline $\begin{array}{c}\text { OK-4; OK-8; OK-9; OK-10; } \\
\text { OK-25; OK-50; OK-51; OK-52; } \\
\text { OK-55 }\end{array}$ & ПК-10 & $\begin{array}{l}\text { OK-3; OK-5; OK-6; OK-25; } \\
\text { OK-37; OK-42; OK-51; OK-52 }\end{array}$ & ПК-10 \\
\hline \multicolumn{2}{|c|}{ Авиационный английский язык } & \multicolumn{2}{|c|}{ Авиационный английский язык } \\
\hline OK-51; OK-52; OK-55 & ПК-10 & $\begin{array}{l}\text { OK-3; OK-5; OK-6; OK-10; } \\
\text { OK-25; OK-37 }\end{array}$ & ПК-10; ПК-25; ПК-37 \\
\hline \multicolumn{2}{|c|}{$\begin{array}{c}\text { Фразеология радиообмена на английском языке } \\
\text { при выполнении полетов }\end{array}$} & \multicolumn{2}{|c|}{ Фразеология радиообмена на английском языке } \\
\hline OK-51 & ПК-10 & $\begin{array}{l}\text { OK-3; OK-5; OK-6; OK-10; } \\
\text { OK-25; OK-37 }\end{array}$ & - \\
\hline \multicolumn{2}{|c|}{$\begin{array}{c}\text { Правила и фразеология радиообмена } \\
\text { при выполнении полетов }\end{array}$} & \multicolumn{2}{|c|}{ Фразеология радиообмена и радиотелеграфия } \\
\hline- & ПК-16; ПК-32; ПК-38 & - & ПК-1; ПК-3; ПК-6 \\
\hline & & \multicolumn{2}{|c|}{ Разговорный английский язык } \\
\hline & & $\begin{array}{l}\text { OK-3; OK-5; OK-6; OK-25; } \\
\text { OK-37; OK-42; OK-51; OK-52 }\end{array}$ & - \\
\hline 9 на все дисциплины & 4 на все дисциплины & 9 на все дисциплины & 6 на все дисциплины \\
\hline
\end{tabular}

\section{Результаты анализа компетентностной модели иноязычного образования будущих пилотов и авиадиспетчеров}

Первое, на что нужно обратить внимание, - это то, что при обучении будущих авиаспециалистов на уровне бакалавриата основной упор делается на формировании ОК. К сожалению, ФГОС ВПО предлагает только одну ПК, напрямую связанную с владением авиационным английским языком, - это ПК-10, причем она дана в предельно широкой формулировке: «Владеть авиационным английским языком в объеме, достаточном для эффективного общения на общие, конкретные и связанные с работой темы» [16]. Самое интересное заключается в том, что она дублирует, причем частично, требования из Шкалы оценки языковых знаний ИКАО, касающиеся исключительно словарного запаса. Ср.: «Словарный запас и правильность его использования, как правило, достаточны для эффективного общения на общие, конкретные и связанные с работой темы. В необычных или неожиданных ситуациях при отсутствии достаточного словарного запаса могут часто использоваться парафразы» [15, с. А-7]. Все остальные ПК, представленные в компетентностных моделях двух вузов ГА (см. Таблицу 2), к английскому языку не имеют прямого отношения. Приведем их в Таблице 3. 
Таблица 3. Формулировки ПК в ФГОС ВПО по направлению подготовки 161000 АЭРОНАВИГАЦИЯ (квалификация (степень) «бакалавр»)

\begin{tabular}{|l|l|}
\hline \multicolumn{1}{|c|}{ Компетенция } & \multicolumn{1}{c|}{ Формулировка } \\
\hline ПК-1 & уметь использовать нормативные правовые документы в своей профессиональной деятельности \\
\hline ПК-3 & $\begin{array}{l}\text { готовность к самостоятельной, индивидуальной работе, принятию ответственных решений в рам- } \\
\text { ках своей профессиональной компетенции }\end{array}$ \\
\hline ПК-6 & $\begin{array}{l}\text { уметь выбирать технические средства и технологии с учетом экологических последствий их } \\
\text { применения }\end{array}$ \\
\hline ПК-16 & способность формулировать профессиональные задачи и находить пути их решения \\
\hline ПК-25 & способность настраивать и осуществлять обслуживание аппаратно-программных средств \\
\hline ПК-32 & способность обеспечивать безопасность полетов воздушных судов и авиационнуюезопасность \\
\hline ПК-37 & $\begin{array}{l}\text { владеть методами и процедурами обеспечения безопасности полетов воздушных судов и ис- } \\
\text { пользования воздушного пространства }\end{array}$ \\
\hline ПК-38 & $\begin{array}{l}\text { готовность выполнять работы по информационному обслуживанию эксплуатации воздушных } \\
\text { судов и объектов авиционной инфраструктуры, организации воздушного движения, аэронави- } \\
\text { гационного обслуживания полетов и использования воздушного пространства с помощью } \\
\text { средств вычислительной техники }\end{array}$ \\
\hline
\end{tabular}

Возникает вопрос: почему вузы, формируя компетентностную модель иноязычного образования, выбирают не имеющие практически никакого отношения к языковой подготовке ПК? Ответ очень прост: в самом ФГОС указана только одна ПК - ПК-10, которая непосредственно связана с английским языком, и она, к сожалению, не отражает всех требований к уровню знаний английского языка будущими пилотами и авиадиспетчерами. Предусматриваемые документом ИКАО такие дескрипторы оценки, как «беглость речи», «понимание», «общение», имеющие самое непосредственное отношение к коммуникативности, по непонятным причинам не находят отражения в формулировке единственной ПК. Это обстоятельство, кстати, имеет одно «неожиданное» методическое следствие. Общеизвестно, что ФГОС предлагает перечень компетенций в качестве ориентира не только для разработки ООП, но также и для составления учебников и учебных пособий. Отсутствие конкретики в обозначенной в ФГОС единственной профессиональной компетенции отражается в самом общем характере и типах заданий, которые мы обнаруживаем в существующих отечественных учебниках и учебных пособиях по дисциплине “Aviation English”. Если исключить характерное лексическое наполнение материала, то, в принципе, они мало чем будут отличаться от аналогичных заданий учебного пособия по английскому языку для специальных целей (English for Specific Purposes, ESP) любого профиля.

Второе, что заслуживает отдельного обсуждения, - это неполный охват проектируемым иноязычным обучением будущих трудовых действий, функций пилотов. Если мы проанализируем квалификационные характеристики пилотов по действующему «Единому квалификационному справочнику должностей руководителей, специалистов и других служащих», то обнаружим, в частности, что в должностных обязанностях капитана воздушного судна совершенно четко прописано, что он «доводит до членов экипажа меры по безопасности полета», «информирует экипаж о текущей высоте полета после пролета высоты начала визуальной оценки и до приземления» [4; 11$]$.

Это трудовое действие вполне согласуется с заявленной в ФГОС ПК-16: «способностью формулировать профессиональные задачи и находить пути их решения». Эта же ПК, так или иначе, согласуется и с трудовыми действиями второго пилота, который осуществляет «прослушивание эфира, настройку и прослушивание позывных радиотехнических средств» [Там же]. Потому, с одной стороны, странным кажется то, что эта ПК включается в компетентностную модель выпускника только одним вузом - СПбГУ ГА и только для дисциплины «Правила и фразеология радиообмена при выполнении полётов», т.е. преимущественно для авиадиспетчеров. С другой стороны, попутно возникает резонный вопрос: возможно ли конкретную трудовую функцию, трудовое действие приравнивать к ПК в ФГОС?

Пилоты, в отличие от авиадиспетчеров, осуществляют речевое взаимодействие не только в условиях непосредственной «производственной ситуации», т.е. полета, но и в поисково-коммуникативной, эксплуатационно-технологической, учебно-научной, учебно-тренировочной и иной деятельности. Можно с уверенностью говорить о том, что авиационный английский язык в практике пилота выступает в первую очередь средством коммуникативного взаимодействия.

«Важной составляющей качественно разработанной обучающей программы, - считает С. А. Мельниченко, - является ее контекстуальное содержание, основанное на знании ситуации использования языка. Владение ситуацией использования языка в авиации достигается за счет изучения профессиональной деятельности пилотов, используемой техники, правил и процедур выполнения полета» [9, с. 145]. Если для авиадиспетчеров диалогическая речь считается основной сферой коммуникации, а, следовательно, доминирующими видами речевой деятельности в учебном курсе являются аудирование и говорение, то при подготовке пилота в равной мере должны отрабатываться все виды речевой деятельности, поскольку только так будет достигнуто принципиальное согласие между предметным содержанием языкового курса и интересами слушателей. Поэтому, ставя вопрос о степени эквивалентности формулировок ПК в ФГОС и конкретных трудовых функций, трудовых действий в ПС, мы даем отрицательный ответ. ПК должна соответствовать по содержанию заявленным в ПС трудовым функциям и действиям, но не обязательно совпадать с ними по своему коммуникативному объему. 


\section{Заключение}

Итак, подведем итоги. Наш краткий анализ позволяет сделать нам следующие выводы:

1. Отсутствие соответствующих профессиональных стандартов для пилота и авиадиспетчера ведет к отсутствию соответствующей национальной «работающей» нормативно-правовой базы в сфере обучения авиационному английскому языку, фразеологии радиообмена, техническому английскому языку и другим, не менее важным специализированным курсам, поскольку не позволяет разработать законодательно одобренный федеральный государственный образовательный стандарт нового поколения.

2. Отсутствие федерального государственного образовательного стандарта нового поколения $(3+, 3++)$ по направлению подготовки «Аэронавигация» не дает возможности разработать надлежащую образовательную программу конкретному вузу, равно как и рабочие программы дисциплин, отражающие современные требования к языковой подготовке авиаспециалиста. Лингводидактические основания действующей образовательной программы следует признать устаревшими.

3. Анализ компетентностной модели выпускника двух вузов, где готовят пилотов и авиадиспетчеров ГА, показывает, что профессиональная составляющая в обучении английскому языку недостаточна. Преобладание общекультурных компетенций в имеющихся сейчас в распоряжении вузов компетентностных моделях неспособно обеспечить необходимый уровень специализированной подготовки на всех этапах обучения.

4. Для улучшения и исправления ситуации, на наш взгляд, небесполезно было бы предварительно провести мониторинг практической реализации коммуникативных умений среди выпускников разных лет.

5. Учитывая сказанное, констатируем, что готовность к выполнению того или иного вида (видов) профессиональной деятельности (трудовых функций) пилота ГА, базирующаяся на его коммуникативной компетенции, которая проектируется действующими ФГОС и ООП, остается под вопросом.

Наши рекомендации по улучшению ситуации в самом общем виде заключаются в следующем. Конечно, принятие соответствующего ПС является главной задачей, поскольку только это позволит получить эффективный ФГОС нового поколения. Необходимо обоснованное дополнение содержания ФГОС нового поколения обязательными профессиональными компетенциями, которые самым непосредственным образом согласовывались бы со всеми дескрипторами языковых умений по квалификационной шкале ИКАО: произношение, конструкции, словарный запас, беглость речи, понимание и общение. В новом ФГОС формулировки профессиональных компетенций будущего пилота ГА должны остаться обобщенными и широкими, но требования к результатам обучения должны быть прописаны более четко и детализировано, поскольку только тогда они будут соответствовать требованиям соответствующего ПС и языковым требованиям ИКАО уровня Language Proficiency Level 4. ФГОС должен заключать в себе возможность конкретизировать требования к результатам обучения на уровне конкретной образовательной программы, иначе они мало или практически не проверяемы. Коммуникативная компетенция будущих пилотов и авиадиспетчеров должна формироваться на протяжении всего периода обучения, причем достичь этого возможно, на наш взгляд, в том числе и за счет «сквозного» увеличения перечня ПК в новом ФГОС, т.е. в стандартах квалификаций «бакалавр» и «магистр». В таком случае под каждую ПК в ООП будет разработана система учебных заданий, методических материалов с подбором нового профессионально ориентированного лингвистического контента на основе индивидуализированных образовательных технологий.

Кроме того, мы считаем нецелесообразным перенос формулировок трудовых функций из ПС в формат профессиональных компетенций в ФГОС и конкретную образовательную программу, так как их трудно будет представить и оценить в карте компетенций как совокупность знаний, умений и навыков. Для того чтобы подобная оценка была адекватной, нужно провести детальный анализ формируемых компетенций, соотнося их, конечно, с указанными рубриками профессионального стандарта, но помня при этом, что университетские программы дисциплин (модулей) обеспечивают только готовность к выполнению того или иного вида (видов) профессиональной деятельности (трудовых функций).

Особого внимания требует, безусловно, коммуникативная компетенция. Она должна быть максимально детализирована, соотнесена с квалификационной шкалой языковых знаний ИКАО и проверяема соответствующим фондом оценочных средств, которые обеспечат контроль уровня ее сформированности. Кроме того, поскольку она в вузах ГА является, по нашему глубокому убеждению, не предметной, а надпредметной, то ее совершенствованию будет способствовать и практика преподавания максимально возможного количества дисциплин профессионального цикла на английском языке.

\section{Список источников}

1. Авиационная электросвязь: международные стандарты, рекомендуемая практика и правила аэронавигационного обслуживания. Приложение 10 к Конвенции о международной гражданской авиации [Электронный ресурc]. URL: http://aerohelp.ru/sysfiles/374_33.pdf (дата обращения: 16.07.2020).

2. Биглов Р. Р. Актуализация учебно-методической документации в связи с введением в действие профессиональных стандартов [Электронный ресурс]. URL: http://umo19.ru/data/documents/Biglov-R.R.-ZaedanieFUMO-no-2.pptx (дата обращения: 16.07.2020).

3. Дарымов Ю. П., Жидовинов А. Ф., Крыжановский Г. А. Диспетчер УвД: автоматизация взаимодействия. М.: Транспорт, 1985. 172 с. 
4. Единый квалификационный справочник должностей руководителей, специалистов и других служащих (ЕКС), 2019 [Электронный ресурс]. URL: http://bizlog.ru/eks/ (дата обращения: 16.07.2020).

5. Мельниченко Н. П. Дорожная карта [Электронный ресурс]. URL: https://aviasafety.ru/33514/ (дата обращения: 16.07.2020).

6. Мельниченко С. ИКАО: требования к владению английским языком будут усилены [Электронный ресурс]. URL: https://aviaenglish.ru/ikao-trebovaniya-k-vladeniyu-anglijskim-yazykom-budut-usileny/ (дата обращения: 16.07.2020).

7. Мельниченко С., Станкович Д. На одном языке: история принятия английского языка в качестве средства общения при ведении радиотелефонной связи // Аэронавигация. 2012. № 1 (22). С. 44-53.

8. Мельниченко С. А. Авиационный английский сквозь призму безопасности полётов [Электронный ресурс]. URL: https://aviasafety.ru/33511/ (дата обращения: 16.07.2020).

9. Мельниченко С. А. Особенности языковой подготовки пилотов гражданской авиации в России // Научный вестник Воронежского государственного архитектурно-строительного университета. Серия «Современные лингвистические и методико-дидактические исследования». 2010. № 13. С. 142-150.

10. О внесении изменений в Трудовой кодекс РФ и статьи 11 и 73 Федерального закона «Об образовании в Российской Федерации» [Электронный ресурс]: Федеральный закон от 02.05.2015 № 122. URL: http://base. garant.ru/71001244/ (дата обращения: 16.07.2020).

11. Об утверждении Единого квалификационного справочника должностей руководителей, специалистов и служащих, раздел «Квалификационные характеристики должностей руководителей и специалистов организаций воздушного транспорта» (с изменениями на 12 февраля 2014 года) [Электронный ресурс]. URL: http://docs.cntd.ru/document/902151376 (дата обращения: 16.07.2020).

12. Образовательные программы [Электронный ресурс]. URL: http://www.uvauga.ru/education/vpo/oprog (дата обращения: 16.07.2020).

13. Основная профессиональная образовательная программа высшего образования. Направление подготовки 25.03.03 Аэронавигация [Электронный ресурс]. URL: https://clck.ru/JjM52 (дата обращения: 16.07.2020).

14. Росавиация проведет конференцию по совершенствованию обучения английскому языку в учебных заведениях ГА и тестирования по шкале ИКАО [Электронный ресурс]. URL: https://www.aviaport.ru/digest/ 2020/02/17/626815.html (дата обращения: 24.06.2020).

15. Руководство по внедрению требований ИКАО к владению языком [Электронный ресурс]. URL: http://rus. ums.rshu.ru/file1480 (дата обращения: 16.07.2020).

16. Федеральный государственный образовательный стандарт высшего профессионального образования по направлению подготовки 161000 Аэронавигация (квалификация (степень) «бакалавр») [Электронный реcypc]. URL: https://base.garant.ru/197464/53f89421bbdaf741eb2d1ecc4ddb4c33/ (дата обращения: 16.07.2020).

17. Херринг Ф. Роль изучения английского языка авиационными специалистами в предотвращении авиационных происшествий // Семинар по предотвращению СИВСП: тезисы докл. и сообщений. М.: Транспорт, 1997. С. 2-22.

18. Шлямова А. А. Педагогические условия языковой подготовки в авиационном вузе // Инновационная наука. 2016. № 1-2 (13). С. 236-238.

19. Языковые требования ИКАО: прогресс или пролёт? [Электронный ресурc]. URL: http://www.shpls.org/ press/news/1431/view/ (дата обращения: 16.07.2020).

20. Lamy P. ICAO study will examine the possibility of developing performance based training // ICAO Journal. 1999. Vol. 54. № 2. P. 4-5.

21. Nurden R. Word that killed 583 people // The European. 1997. № 3.

22. Popa C. ICAO Language Proficiency Requirements: Occurrence, Developments and Associated Documents [Электронный ресурс] // ICAO Safety Report 2019. URL: https://www.icao.int/safety/Documents/ICAO_SR_ 2019_final_web.pdf (дата обращения: 16.07.2020).

\section{Информация об авторах | Author information}

RU Лебедева Наталья Александровна ${ }^{1}$, к. ист. н., доц.

${ }^{1}$ Санкт-Петербургский государственный университет гражданской авиации

EN Lebedeva Natalia Alexandrovna ${ }^{1}, \mathrm{PhD}$

${ }^{1}$ St. Petersburg State University of Civil Aviation

${ }^{1}$ lebedevanatali@inbox.ru

\section{Информация о статье | About this article}

Дата поступления рукописи (received): 28.06.2020; опубликовано (published): 30.10.2020.

Ключевые слова (keywords): компетентностная модель; английский язык; профессиональная деятельность авиаспециалистов; шкала оценки языковых знаний; авиационный вуз; competence-based model; English language; airmen's professional activity; language proficiency rating scale; aviation university. 